\title{
Tobacco control activities of primary-care physicians in the Community Intervention Trial for Smoking Cessation
}

Division of Preventive and Behavioral Medicine, University of Massachusetts Medical School, Worcester, Massachusetts, USA J K Ockene

Community Health Research Unit, Department of Epidemiology and Community Medicine, University of Ottawa, Ottawa, Ontario, Canada

E A Lindsay

Department of Psychiatry, New Jersey Medical School, Newark, New Jersey N Hymowitz

Information Management Services, Inc., Silver Spring,

Maryland

C Giffen

Division of Preventive and Behavioral

Medicine, University

of Massachusetts

Medical School,

Worcester,

Massachusetts

T Purcell

Department of

Preventive and

Environmental Health

Medicine, University

of Iowa, Iowa City,

Iowa

P Pomrehn

Center for Disease Control, Atlanta,

Georgia

T Pechacek

Correspondence to:

Dr Judith K Ockene,

Division of Preventive and Behavioral Medicine, University of Massachusetts Medical School, 55 Lake Avenue, North, Worcester, Massachusetts 01655, USA; email:

JOckene@banyan.ummed.edu
Abstract

Objective-To compare tobacco control practices of physicians and their staff in Intervention communities with those in Comparison communities of the Community Intervention Trial for Smoking Cessation (COMMIT).

Design-COMMIT was a randomised trial testing community-based intervention for smoking cessation carried out over four years.

Setting-Eleven matched pairs of communities assigned randomly to Intervention and Comparison conditions.

Participants and interventions-Physicians in the Intervention communities participated in continuing medical education (CME). Training for office staff focused on tobacco control and office intervention "systems".

Outcome measures-Smoking control attitudes and practices reported by primary-care physicians in the 22 communities, smoking policies, and practices of 30 randomly selected medical offices in each community, and patient reports of physician intervention activities.

Results-Response rates to the physicians' mail survey were $45 \%$ and $42 \%$ in Intervention and Comparison communities, respectively. Telephone interviews of office staff had response rates of $84 \%$ in both conditions. Physicians in Intervention communities were more likely to attend training than those in Comparison communities $(53 \%$ and $26 \%$, respectively $(\mathbf{P}<0.0005))$. In both conditions, training attendees perceived themselves as being better prepared to counsel smokers than non-attendees $(P \leqslant 0.01)$ and reported more activity in smoking intervention. Intervention communities carried out more office-based tobacco control activities $(P=0.002)$. Smokers in Intervention communities were more likely to report receiving reading material about smoking from their physicians $(P=0.026)$. No other differences in physician intervention activities were reported by smokers between the Intervention and Comparision communities.

Conclusions-The COMMIT intervention had a significant effect on some reported physician behaviours, office practices, and policies. However, most physicians still did not use state-of-the-art smoking intervention practices with their patients and there was little, or no, difference and there watient reports of intervention activities of physicians in the Intervention and Comparison communities. Better systems and incentives are needed to attract physicians and their staff to CME attract physicians and the encourage them to follow through on what they learn. The recently released Agency for Health Care Policy and Research clinical practice guideline for smoking cessation and other standards and policies outline these systems and offer suggestions for incentives to facilitate adoption of these practices by physicians.

(Tobacco Control 1997;6 (suppl 2):S49-S56)

Keywords: smoking cessation; COMMIT; primary-care physicians

\section{Introduction}

In 1987, the National Cancer Institute (NCI) embarked on the largest community smoking cessation trial ever conducted. This trial, the Community Intervention Trial for Smoking Cessation (COMMIT), ${ }^{1}$ included 11 matched pairs of communities (22 communities) throughout North America randomly assigned to the Intervention or the Comparison condition. In the Intervention communities, the role of healthcare providers in the smoking intervention arena was emphasised within the context of community-wide activities. Special education/training programmes were used to "mobilise" physicians and their offices. Leaders among the healthcare providers also were encouraged to take an active role in "train the trainer" programmes offered by the NCI, and to become "local experts" in tobacco control clinical interventions.

The total local and national physician training activities make COMMIT the largest randomised trial of continuing medical education (CME) reported to date on any health issue in the United States. This paper will report on the smoking intervention practices of physicians and their offices in the Intervention and Comparison communities in the COMMIT to help determine the effect of the physician training activities on physician behaviours.

Studies conducted over the past 10 years have established that there is an important role for physicians in smoking cessation. ${ }^{3}$ The 
recently released Agency for Health Care Policy and Research (AHCPR) clinical practice guideline for smoking cessation ${ }^{4}$ recommends that every patient who smokes should be offered smoking cessation treatment at every office visit. The impact of a single physician on smoking rates may be small but, if applied consistently by most physicians, the population effect could be substantial.

Cessation outcomes have been investigated in randomised, controlled trials ${ }^{6-14}$ of physicians who received special training to help smokers during the course of their regular medical encounters. Approaches tested in these trials included setting a quit date, prescribing nicotine replacement therapy, providing self-help materials, and providing follow-up contact. In almost all of the studies, physicians also were prompted or "cued" to intervene with smokers-for example, by chart stickers. These studies and others noted in the AHCPR review ${ }^{4}$ demonstrated that physician education/training can have a positive impact on physician smoking intervention practices. However, the teaching of a structured intervention approach must be coupled with implementation of office systems to cue physicians and monitor smokers. Recent reviews of the CME literature ${ }^{1516}$ of randomised trials addressing a wide range of physician-delivered preventive counselling practices also concluded that changes in physician practices occurs only when a traditional educational programme is accompanied by "enabling" strategies in the office practice.

Although the above studies have demonstrated the efficacy of physician interventions with smokers under well-controlled experimental conditions, only one study ${ }^{5}$ investigated the effectiveness of these interventions in natural community settings. In the natural setting there is generally no follow-up support for the use of new procedures learned in CME, nor is there control over what is done in the practice. Crooks and colleagues ${ }^{5}$ indicated no significant changes in attitudes, practices, and involvement in tobacco control efforts for physicians who had received $\mathrm{CME}$ for smoking intervention and were working under natural practice conditions.

In the COMMIT Intervention communities, physicians and their office staff were invited to participate in educational/training programmes, and pamphlets, brochures, resource guides, and other materials were made available to them. As a community experiment in an uncontrolled environment, the level and nature of education/training implemented in COMMIT is more generalisable to the usual community setting than is the intensive organisational control and follow-up support provided in the more rigorously controlled efficacy studies. Therefore, health departments or other agencies, such as healthcare organisations that have funding for tobacco control activities, could readily follow the COMMIT model. To further assist with this, the AHCPR guideline provides easy-to-follow steps for physicians and healthcare administrators to take in imple- menting a system that promotes interventions for smoking.

\section{Methods}

INTERVENTION

The COMMIT provided a standard protocol that had necessary flexibility to accommodate local variations in the Intervention communities. There were 58 specified activities to be implemented in the four channels for intervention: worksites and other organisations, cessation services, public education, and healthcare providers. ${ }^{217-19}$ The overall goal for the healthcare providers was to increase the quality and quantity of their intervention with smokers. $^{2}$

There were three levels of training activities provided for physicians: basic, comprehensive, and "train the trainers". A fourth type of training was available to staff in physicians' offices. The protocol provided guidelines for the length and content of training but the frequency and format of training varied according to each community's needs. ${ }^{2021}$ Basic training included a minimum of 45-minute didactic presentations on tobacco and the use of the NCI "4As" (Ask, Advise, Assist, Arrange) counselling model. ${ }^{2}$ Comprehensive training included a minimum of 2.5 hours of training, which included didactic presentations on tobacco, use of the $4 \mathrm{~A}$ counselling model, office systems, and skill building exercises (role play). The recommended office practices to facilitate smoking intervention were: designating and providing someone as a smoking coordinator; creating a non-smoking office environment; identifying patients who smoke; addressing cessation with all smoking patients; and intervening with smoking patients. Instruction to physicians emphasised their use of the following four steps (the "4 As") with patients: $A s k$ if they smoke; Advise the need to stop smoking; Assist by offering self-help materials, setting of a smoking cessation date and offering nicotine replacement therapy for those patients who are nicotine dependent; and Arrange follow-up support. ${ }^{2}$ Instruction to office staff emphasised creating a non-smoking environment and setting up a system to identify smokers and to cue physicians to intervene.

All of the intervention channels in COMMIT followed set process and impact objectives for protocol activities. The process objectives for the healthcare providers channel were that $80 \%$ of physicians in each Intervention community would attend basic training and $25 \%$ would attend comprehensive training in addition to the basic training. The impact objectives were set to assess whether the recommended intervention activities actually reached patients. For example, it was projected that $25 \%$ of physicians would report setting "stop smoking" dates with patients most of the time and $25 \%$ of smokers would report being asked to set a "stop smoking" date. Another impact objective was that $60 \%$ of patients who smoke would report that their physicians advised them to stop smoking. 
Table 1 Targeted physicians participating in basic and comprehensive training by Table 1 Targeted physicians participating in basic and

\begin{tabular}{lcccc}
\hline Community & $\begin{array}{l}\text { Physicians } \\
n\end{array}$ & $\begin{array}{l}\text { Physician officest } \\
n\end{array}$ & $\begin{array}{l}\text { Basic training } \\
\%\end{array}$ & $\begin{array}{l}\text { Comprihensive training } \\
\%\end{array}$ \\
\hline 1 & 120 & 29 & 72 & 13 \\
2 & 72 & 68 & 92 & 35 \\
3 & 92 & 43 & 67 & 23 \\
4 & 104 & 46 & 77 & 43 \\
5 & 203 & 131 & 80 & 6 \\
6 & 123 & 60 & 100 & 24 \\
7 & 155 & 105 & 90 & 21 \\
8 & 82 & 42 & 56 & 18 \\
9 & 165 & 75 & 81 & 25 \\
10 & 96 & 40 & 84 & 30 \\
11 & 71 & 34 & 97 & 38 \\
Average overall & 1283 & 673 & 81 & 25 \\
\hline
\end{tabular}

*Targeted physicians: all physicians in the community practising family, general, or internal medicine, cardiology, pulmonology, obstetrics/gynaecology, or osteopathy. me number of offices in the community where targeted physicians practice.

\section{ASSESSMENT}

A computerised programme record-keeping system was used by project staff at each site to track protocol activities during the intervention period. ${ }^{22}$ Therefore, it is possible to determine what percentage of targeted physicians actually attended educational/training events.

To assess reported smoking intervention practices of the physicians in the Intervention and Comparison communities, a 14-item survey was mailed to each targeted physician (physicians practising family, general, or internal medicine, cardiology, pulmonology, obstetrics/gynaecology, or osteopathy). Physicians were prompted to respond to the mailed questionnaire through a postcard reminder sent two weeks after the first mailing. After four weeks, non-respondents were mailed another copy of the questionnaire, followed by a postcard reminder. The average number of physicians per community included in the initial mailing was 100 .

Telephone surveys of office practice in a sample of 30 randomly selected targeted physicians' offices in each community also were conducted. Offices were randomly selected from lists compiled from the telephone book

Table 2 Physicians surveys: reported practices of physicians by study condition *

\begin{tabular}{|c|c|c|c|}
\hline \multirow[b]{2}{*}{ Smoking intervention activities } & \multicolumn{2}{|c|}{ Post-intervention survey (\%) } & \multirow[b]{2}{*}{$P$} \\
\hline & $\begin{array}{l}\text { Intervention } \\
(n=465)\end{array}$ & $\begin{array}{l}\text { Comparison } \\
(n=404)\end{array}$ & \\
\hline Routinely asks new patients about smoking & 95.8 & 95.9 & 0.560 \\
\hline \multicolumn{2}{|l|}{$\begin{array}{l}\text { Routinely asks old patients about } \\
\text { Stickers or other markers used for identifying smoking }\end{array}$} & & 0.318 \\
\hline Explain dangers of smoking $† \ddagger$ & 89.4 & 89.0 & 0.438 \\
\hline Advise to stop smoking $† \neq$ & 98.4 & 94.0 & 0.009 \\
\hline Set quit date $\ddagger$ & 21.8 & 14.4 & 0.004 \\
\hline Develop cessation plan $¥ \ddagger$ & 38.1 & 37.4 & 0.424 \\
\hline Provide self-help materials $† \ddagger$ & 48.2 & 42.3 & 0.048 \\
\hline Make referrals $\ddagger$ & 21.5 & 22.1 & 0.550 \\
\hline Recommend nicotine replacement therapytł & 51.7 & 42.1 & 0.048 \\
\hline Arrange follow-up visitt & 19.2 & 17.9 & 0.297 \\
\hline Record results of encounter in medical record $\nmid \ddagger$ & 65.7 & 60.0 & 0.172 \\
\hline \multicolumn{4}{|l|}{ Average time spent counselling patients (minutes) } \\
\hline $\begin{array}{l}\text { Do not try } \\
1-2\end{array}$ & 6.9 & 8.0 & 0.699 \\
\hline $\begin{array}{l}1-2 \\
>3\end{array}$ & 1.4 & 0.08 & \\
\hline$>3$ & 91.8 & 91.1 & 0.399 \\
\hline $\begin{array}{l}\text { Attended training in smoking cessation in past } 4 \text { years } \\
\text { Participation in tobacco control activity outside the }\end{array}$ & 52.6 & 26.1 & 0.001 \\
\hline \multicolumn{3}{|l|}{ Participation in tobacco control activity outside the } & 0.065 \\
\hline $\begin{array}{l}\text { oftice } \\
\text { Average tobacco action score }\end{array}$ & 4.8 & 4.4 & 0.01 \\
\hline
\end{tabular}

*Percentage equals mean percentage, with the community as the unit of analysis.

Item included in tobacco action score; range $(0-10)$; each item awarded 1 point.

$\ddagger$ Respondents who answered that they did this "most" or "all of the time". for the Intervention and Comparison communities. The telephone survey included 15 items to assess smoking policies, availability of health education and self-help materials, and monitoring of smokers. Community research analysts completed the interview by telephone. To determine who to interview in an office, interviewers asked for the office manager, read him/her the introduction to the survey, and asked to speak with the most appropriate member of the office to complete the survey.

The initial set of surveys of physicians and of physicians' offices was conducted only in the Intervention communities to avoid influencing physicians in the Comparison communities. ${ }^{21}$ Hence, there was no pre-test information for the Comparison communities. The initial surveys in Intervention communities occurred in February 1990 (16 months after the community intervention began). Postintervention surveys were conducted in April 1993 in both the Intervention and Comparison communities.

The endpoint cohort survey was also used to provide data for this paper. ${ }^{22}$ Before randomisation of the communities in 1988, this large-scale telephone survey, designed to provide baseline smoking prevalence estimates and to identify a cohort of residents to be tracked annually, was conducted in each community using modified, random digit dialling technology. An average of 5400 households was contacted in each community, from which approximately 550 heavy smokers and $\mathbf{5 5 0}$ light-to-moderate smokers between 25 and 64 years of age were identified for cohort membership. Of these smokers, an $80 \%$ random sample (440 from each group in each of the 22 communities) formed the endpoint cohort, and the remaining $20 \%$ formed the evaluation cohort. ${ }^{23}$ In 1993, at the final annual contact, participants in the endpoint cohort were asked a series of questions to assess intervention and programme awareness. They were asked their smoking status, and whether their physicians asked them whether or not they smoked, advised them to stop smoking, asked them to set a quit date, gave them any pamphlets about smoking, or prescribed nicotine replacement therapy. The endpoint survey was not limited to smokers who had visited the physicians who had responded to the COMMIT mail and telephone surveys.

COMPOSITE MEASURES

To quantify physicians' smoking intervention practices, a tobacco action score was created. This score is computed by allotting one point for each of 10 recommended practices asked about in the physician survey (see table 1 for a list of the practices included). The maximum score is 10 .

A second composite score, the tobacco control score, was computed for the office tobacco control policies and activities by allotting 0 or 1 point for each of nine recommended practices and policies asked about in the office practice survey (see table 4 for a list of the practices included). ${ }^{21}$ The score for the office smoking policy incorporates both restrictiveness of 
Tabl 3 Relationship between attendance at smoking intercintion training and perceptions regarding preparedness*

\begin{tabular}{|c|c|c|c|c|c|c|c|c|}
\hline \multirow{4}{*}{$\begin{array}{l}\text { Hoi: prepared do you } \\
\text { feel to counsel smokers? }\end{array}$} & \multicolumn{8}{|c|}{ Attended training } \\
\hline & \multicolumn{4}{|c|}{ Interventiont } & \multicolumn{4}{|c|}{ Comparisont } \\
\hline & \multicolumn{2}{|c|}{ Yes } & \multicolumn{2}{|c|}{ No } & \multicolumn{2}{|c|}{ Yes } & \multicolumn{2}{|c|}{ No } \\
\hline & $n$ & $\%$ & $n$ & $\%$ & $n$ & $\%$ & $n$ & $\%$ \\
\hline Very well & 134 & 54.9 & 81 & 37.2 & 65 & 58.0 & 110 & 38.5 \\
\hline Somewhat & 106 & 43.4 & 113 & 51.8 & 46 & 41.1 & 155 & 54.2 \\
\hline Not well/definitely not & 4 & 1.6 & 24 & 11.0 & 1 & 0.9 & 21 & 7.3 \\
\hline
\end{tabular}

*Percentage equals overall percentage with the physician as the unit of analysis. $+P>0.001$.

policy and degree of enforcement. A full point is awarded if an office reported a total ban which is strictly enforced; less than a total ban is assigned a score of 0 ; and total bans which are occasionally disobeyed are assigned partial credit. The office tobacco control policies and activities and scores for each were determined by the COMMIT researchers during protocol development. The points assigned reflect the degree of difficulty and commitment to smoking control activities. The maximum total score is 5.0 .

POPULATION ESTIMATES

Outcome variables from the endpoint cohort survey were analysed using weighted population estimates to adjust for sampling design and non-response to the initial survey. These estimates were obtained separately for each community, and included adjustments for the telephone sample selection and for the relevant population subgroups (heavy smokers, light-to-moderate smokers). Resulting estimates, stratified by age and sex, were standardised to community-specific age and sex distributions from the 1990 census (1991 in Canada).

STATISTICAL ANALYSIS

Data presented in this paper were stored and analysed on the IBM mainframe computer facility at the National Institutes of Health (NIH), Bethesda, Maryland. As the design of the COMMIT trial was based upon the community as the unit of randomisation and of intervention, all analyses examining differences between community conditions were produced using the community as the unit of analysis. Responses to each question therefore were averaged for each community, and the differences between the means were computed for each community pair. Analyses of the significance of community pair differences thus computed were generated using one-tailed permutation tests. ${ }^{24}$ The permutation method was used for all primary analyses of COMMIT intervention effect. ${ }^{23}$ The permutation test was chosen not because it is more sensitive than other tests-for example, the $t$ test-but because it is non-parametric and does not assume a normal distribution of data. For the analyses of the significance of differences between heavy smokers and light-to-moderate smokers presented in table 1, two-tailed permutation tests were used. The only exceptions to community-level analyses are the intra-conditional analyses shown in tables 2 and 3, which were produced from individual-level data using the tabulation and $\chi^{2}$ functions of Statistical Analysis Software (SAS). ${ }^{25}$

\section{Results}

PROGRAMME RECORDS SYSTEM

The protocol required mean participation rates for physicians of $80 \%$ and $25 \%$ for basic and comprehensive training, respectively. This rate was achieved overall-however, there was considerable variance in the actual attendance in the communities. For example, there was a range of participation in comprehensive training of $6-43 \%$. Seven out of the 11 communities reached the basic training goal and two others were very close. Only five of the 11 communities reached the comprehensive training goal (table 1). COMMIT staff offered training for support staff in the offices of the physicians; only $30 \%$ reported attending training which was sometimes carried out as a special event but often occurred in the offices.

\section{PHYSICIAN SURVEY}

The response rate for the 1993 physician survey was $45.0 \%$ (range $19.8-64.8 \%$ ) and $42.0 \%$ (range $10.6-61.7 \%$ ) in the Intervention and Comparison communities, respectively. The response rate was based upon the complete sample of physicians identified as practising in the community. Although less than optimum, particularly in the several communities with rates less than $25 \%$, the rates are consistent with prior mail survey research. ${ }^{26-28}$ Past surveys of physicians indicated minimal differences between early respondents and later respondents (those who may have been prompted to respond in this study if more aggressive follow-up procedures had been employed). ${ }^{26-28}$ There were no significant differences in the percentage of the primary-care specialties of the responding physicians. Seventy per cent of the physicians from both conditions were in family practice, general medicine, and internal medicine. Over half of the participants had graduated from medical school in the 1960s and 1970s. Only $1.7 \%$ of the physicians were smokers. Respondents estimated that $28.0 \%$ of their patients smoke, which is slightly above the 1992 national average of $26.5 \% .^{29}$

A high proportion (96\%) of the participating physicians in both conditions reported that they routinely ask new patients about smoking, and a somewhat smaller proportion $(79 \%)$ ask established patients (table 2). Physicians in the Intervention communities were significantly more likely to report advising patients to stop smoking $(P=0.009)$, encouraging patients to set a quit date $(P=0.004)$, recommending nicotine replacement therapy $(P=0.05)$, and providing self-help smoking cessation materials $(P=0.05)$. For each of these reported practices, with the exception of setting a quit date, physicians in the Intervention communities demonstrated significant increases in the post-intervention survey compared with the baseline survey. ${ }^{30}$ Physicians in both conditions 


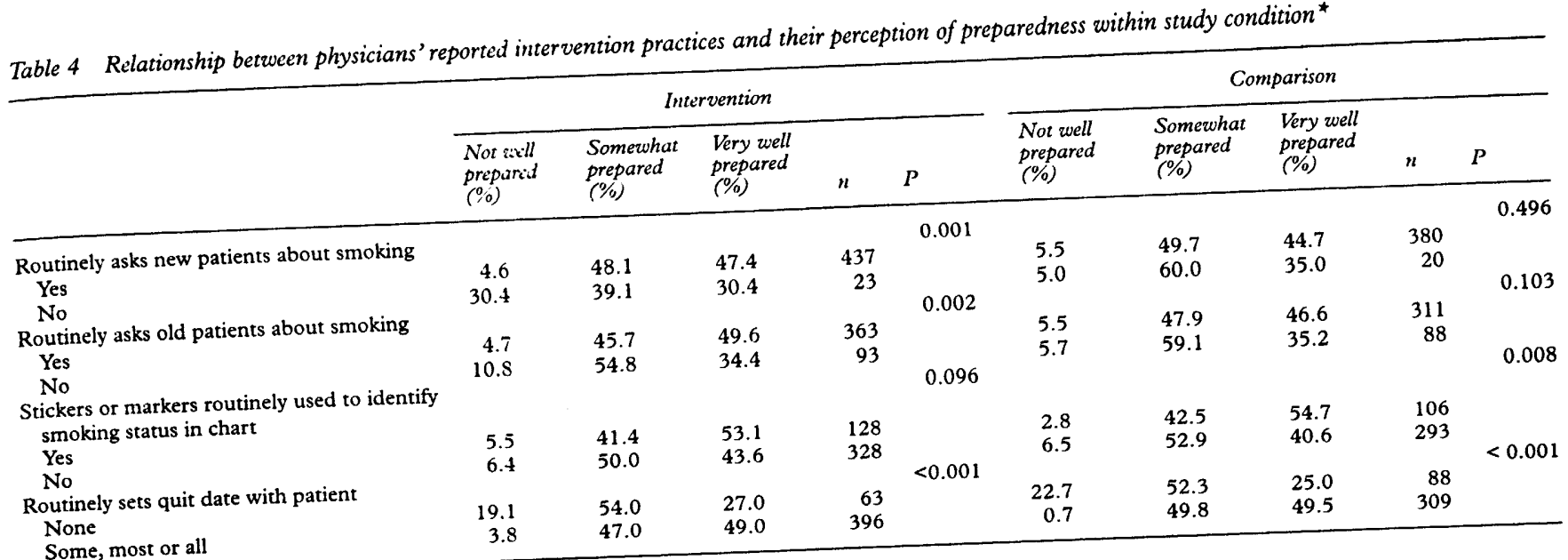

Some, most or all

* Percentage equal to overall percentage with the physician as the unit of analysis.

were unlikely to have a system for identifying patients who smoke and tended to provide advice rather than actual behavioural assistance/intervention (table 2). The tobacco action score, or the level of active cessation assistance, was significantly larger for physicians in the Intervention communities than for physicians in the Comparison communities ( 4.8 vs $4.4 ; \mathrm{P}=0.01$ ).

Physicians in the Intervention communities were significantly more likely to report having attended a training event in the past four years $(P=0.001)$ than physicians in the Comparison communities. In both Intervention and Comparison communities, there was a significant relationship between participation in training events and perceptions of preparedness by physicians $(\mathrm{P}<0.001$ ) (table 3 ).

In both Intervention and Comparison communities, the physicians who reported feeling "not prepared" were least likely to report performing recommended intervention practices (table 4).

PHYSICIAN OFFICE PRACTICE SURVEY

The overall response rate for the telephone office practice survey was $84 \%$ in both the Intervention and Comparison communities. Three hundred and six physician offices participated in the survey in the Intervention communities, and 303 offices participated in the Comparison communities. The median number of patients treated per week was 120 and 100 in the Intervention and Comparison community offices, respectively. Overall, $58.4 \%$ of the offices in both conditions had only one physician $55.1 \%$ and $61.6 \%$ in the Intervention and Comparison communities, respectively). The mean number of nurses practising with physicians was 2.0 in the Intervention communities and 1.6 in the Comparison communities. However, there was a considerable variation across the 22 communities. The diversity is of note because of the implications for feasibility of implementing office smoking control intervention activities in some offices in the Intervention communities. For example, $36 \%$ of the practices had no nurses.

Table 5 shows the tobacco control activities reported in the office practice survey. In Intervention and Comparison communities, a high proportion of offices banned smoking (96\% and $92 \%$, respectively; $P=0.01$ ). A significantly higher proportion of offices in the Intervention communities reported that they posted no-smoking signs $(P=0.03)$ and anti-smoking posters $(P=0.02)$, and provided stop-smoking pamphlets $(\mathrm{P}=0.02)$, local cessation resource guides $(P=0.02)$, and materials for the Great

Table 5 Office practice survey: tobacco control activites in physician offices by study condition *

\begin{tabular}{|c|c|c|c|c|}
\hline \multirow[b]{2}{*}{ Tobacco control activities } & \multicolumn{2}{|r|}{$\begin{array}{l}\text { Intervention } \\
(n=305)\end{array}$} & $\begin{array}{l}\text { Comparison } \\
(n=302)\end{array}$ & \multirow[b]{2}{*}{$P$} \\
\hline & $\begin{array}{l}\text { Baseline } \\
(\%)\end{array}$ & $\begin{array}{l}\text { Pre-intervention } \\
(\%)\end{array}$ & $\begin{array}{l}\text { Post-intervention } \\
(\%)\end{array}$ & \\
\hline $\begin{array}{l}\text { Smoking banned } \\
\text { Smoking allowed by staff only }\end{array}$ & 81.7 & 95.9 & 91.5 & 0.014 \\
\hline $\begin{array}{l}\text { Smoking allowed by staff only } \\
\text { Other }\end{array}$ & 11.4 & 2.6 & 5.4 & \\
\hline $\begin{array}{l}\text { Other } \\
\text { Have a staff person assigned to counsel patients who }\end{array}$ & $\begin{array}{r}6.9 \\
12.6\end{array}$ & $\begin{array}{r}1.4 \\
14.6\end{array}$ & $\begin{array}{r}3.1 \\
14.5\end{array}$ & 0.492 \\
\hline $\begin{array}{l}\text { smoke } \\
\text { Have a no-smoking sign in waiting room }\end{array}$ & & & & \\
\hline $\begin{array}{l}\text { Have a no-smoking sign in waiting room } \\
\text { Have anti-tobacco posters in waiting room }\end{array}$ & $\begin{array}{l}75.6 \\
42.7\end{array}$ & $\begin{array}{l}77.0 \\
47.8\end{array}$ & 67.1 & $\begin{array}{l}0.027 \\
0.015\end{array}$ \\
\hline & $\begin{array}{l}42.7 \\
64.0\end{array}$ & $\begin{array}{l}47.8 \\
78.6\end{array}$ & 35.6 & $\begin{array}{l}0.015 \\
0.023\end{array}$ \\
\hline $\begin{array}{l}\text { Have self-help guides in waiting room } \\
\text { Have cessation resources guides }\end{array}$ & $\begin{array}{l}64.0 \\
49.8\end{array}$ & $\begin{array}{l}78.6 \\
61.7\end{array}$ & 69.0 & $\begin{array}{l}0.023 \\
0.022\end{array}$ \\
\hline $\begin{array}{l}\text { Have cessation resources guides } \\
\text { Place stickers on medical charts }\end{array}$ & 49.8 & $\begin{array}{l}61.7 \\
19.8\end{array}$ & 45.6 & $\begin{array}{l}0.022 \\
0.524\end{array}$ \\
\hline $\begin{array}{l}\text { Place stickers on medical charts } \\
\text { Distribute literature for Great American Smokeout }\end{array}$ & & $\begin{array}{l}19.8 \\
54.1\end{array}$ & $\begin{array}{l}20.0 \\
35.7\end{array}$ & $\begin{array}{l}0.524 \\
0.002\end{array}$ \\
\hline $\begin{array}{l}\text { Distribute literature for Great American Smokeout } \\
\text { Attended training }\end{array}$ & & $\begin{array}{l}54.1 \\
30.3\end{array}$ & $\begin{array}{r}35.7 \\
8.3\end{array}$ & $\begin{array}{l}0.002 \\
0.002\end{array}$ \\
\hline $\begin{array}{l}\text { Attended training } \\
\text { Tobacco control score }\end{array}$ & 1.5 & 2.2 & $\begin{array}{l}8.3 \\
1.8\end{array}$ & 0.002 \\
\hline
\end{tabular}

*Percentage equals mean percentage with the community as the unit of analysis.

Total tobacco control score-range 0-5 with the following elements contributing to the score (points and ele counsel patients; 0.25 -no 1.00-pressure of a total smoking ban, weighted by degree of conforcement; 1.00 - person assigned to coun-stickers on charts of smoking signs; 0.25 -anti-tobacco posters; 0.25 -self-help guides; 0.25 -cessation mer attended training programme. 
int cohort reports of physicians' intervention efforts for light-to-moderate $(L / M)$ and heavy $(H)$ smokers, by study condition ${ }^{\star}$

\begin{tabular}{|c|c|c|c|c|c|c|c|c|c|}
\hline \multirow[b]{2}{*}{ Question } & \multicolumn{2}{|c|}{ Intervention } & \multicolumn{2}{|c|}{ Comparison } & \multicolumn{2}{|c|}{$\begin{array}{l}\text { Difference between } \\
\text { Intervention and } \\
\text { Comparison }\end{array}$} & \multicolumn{2}{|c|}{$\begin{array}{l}\text { One-tailed } \\
\text { permutation test for } \\
\text { difference by } \\
\text { condition }\end{array}$} & \multirow{2}{*}{$\begin{array}{l}\text { Orerall two-tailed } \\
\text { permutation test for } \\
\text { difference } H \text { vs } L / M\end{array}$} \\
\hline & $\begin{array}{l}L / M \\
(\% / q)\end{array}$ & $\begin{array}{l}H \\
(\%)\end{array}$ & $\begin{array}{l}L / M \\
(\%)\end{array}$ & $\begin{array}{l}H \\
(\%)\end{array}$ & $\begin{array}{l}L / M \\
(\%)\end{array}$ & $\begin{array}{l}H \\
(\%)\end{array}$ & $\begin{array}{l}L / M \\
(\%)\end{array}$ & $\begin{array}{l}H \\
(\%)\end{array}$ & \\
\hline $\begin{array}{l}\text { Asked about smoking } \\
\text { Advised to stop }\end{array}$ & 72.3 & 77.6 & 73.0 & 77.5 & -0.8 & 0.1 & 0.368 & 0.467 & $<0.001$ \\
\hline $\begin{array}{l}\text { Set a quit date } \\
\text { Recommended }\end{array}$ & 10.1 & 15.1 & 9.9 & 14.2 & 0.1 & & 0.230 & 0.276 & $<0.001$ \\
\hline $\begin{array}{l}\text { nicotine replacement } \\
\text { See your physician to }\end{array}$ & 20.4 & 30.6 & 19.8 & 29.5 & 0.6 & 1.1 & 0.230 & 0.210 & \\
\hline stop smoking & 16.5 & 23.6 & 15.3 & 23.4 & 1.3 & 0.3 & 0.087 & 0.432 & $<0.001$ \\
\hline
\end{tabular}

Data represents weighted population estimates. Percentage equals mean percentage with the community as the unit of analysis.

American Smokeout $(P=0.002)$. The average tobacco control score for medical offices was 2.2 out of the possible 5 for the Intervention communities, and 1.8 for the Comparison communities $(P=0.002)$. There was a significant improvement in all of the office system activities when the 1990 office practice survey (previously published) ${ }^{30}$ is compared with the 1993 survey for the Intervention communities, lending support to the likelihood that these are actual changes in office practices as a result of education.

ENDPOINT COHORT SURVEY

In the 1993 endpoint cohort survey, $66 \%$ of a possible 20347 people provided smoking outcome data and $57 \%$ provided information on physician intervention. These smokers responded to questions about whether their physicians provided assistance with cessation (table 6). More smokers from the Intervention communities reported receiving pamphlets about smoking than those in the Comparison communities $(P=0.026)$. No other differences were found between conditions. Over $70 \%$ of all smokers reported being asked about their smoking, although less than half of light-to-moderate smokers had been advised to stop smoking while over half of heavy smokers reported such advice. Across both conditions, all of the physician intervention activities were reported more frequently by heavy smokers $(P<0.001)$

\section{Discussion}

The outcomes in this study indicate that teaching physicians preventive counselling interventions for smoking cessation had a positive impact on their reported intervention practices. However, patient reports failed to confirm this finding. Physicians in both conditions who attended training programmes reported that they felt more prepared to intervene on smoking, and they reported more active involvement in smoking intervention than physicians who did not attend the training events.

Most physician respondents in the Intervention and Comparison communities reported that they ask their patients about smoking, explain the dangers of smoking to them, and advise them to stop smoking. Relatively few
$(<50 \%)$ physicians in either condition reported taking a more active role in helping their patients to stop smoking, although physicians in the Intervention communities did somewhat better than those in the Comparison communities. The setting of a smoking cessation date with patients is an integral part of the cessation plan, and is recommended in the AHCPR guideline for smoking cessation. ${ }^{4}$ The frequency of this practice was selected as a marker of whether physicians received the training designed for them. Even in the Intervention condition, the proportion of physicians who reportedly set smoking cessation dates with their patients was low. Very likely, shortcomings in this area account for the fact that relatively few patients in the Intervention communities reported that their physician tried to help them stop smoking.

The physician survey indicated that few physicians set up an office system to identify patients who smoke. Past studies show that without an office system that cues physicians to intervene, there is no measurable change in physician practices or in patient behaviour, even when physicians are taught to intervene. ${ }^{15} 31$ As was noted earlier, the AHCPR guideline ${ }^{4}$ recommends that healthcare systems be modified to identify routinely tobacco users at every visit.

Because education/training was not controlled by COMMIT investigators, the quality of education provided through basic and comprehensive training varied. Although there were standard materials and similar training for faculty, as well as criteria for each level of training, in an effort to maximise the number of physicians receiving training the format was tailored to reach individual physicians. Some training occurred in large seminars at central locations, some in grand rounds at local healthcare institutions, and some in physicians' offices. The diversity of training approaches may account for why only $53 \%$ of physicians surveyed reporting attending training programmes even though programme records indicated that the proportions were closer to $80 \%$.

As the response rates in the mail physician survey in the Intervention and Comparison communities was less than $50 \%$, the respondents most likely represent the most 
actively involved physicians in each community. Although several studies have indicated that this bias would not involve broad demographic or practice characteristics, ${ }^{27} 2832$ an analysis of non-respondents in a mail survey of California physicians showed that physicians who responded to a mail survey were significantly more involved in smoking intervention than those who did not respond.' Hence, the reported rates from the mail survey most likely overestimate the rates of tobacco control activities in the communities. Nevertheless, the similarity of response rates between conditions and the randomised design minimise the degree of bias in the present data set.

Office system changes can be made to happen in efficacy studies, but in every day practice, or in an effectiveness study such as COMMIT, it is rare that a system is set up in the practice after a physician returns from intervention training. Therefore, even if physicians were better trained in the Intervention communities than in the Comparison communities, actual implementation of what they learned was not likely to occur. ${ }^{91633}$

Although physicians in the Intervention communities reported carrying out significantly more interventions on smoking than did physicians in the Comparison communities, respondents to the endpoint cohort reported that physicians from each condition engaged in similar amounts of smoking intervention. Unfortunately, the physician and patient data were not linked. That is, the people responding to the endpoint survey were not necessarily patients of the physicians who answered the physician survey. Therefore, the discrepancy between physician and patient responses cannot be interpreted. The discrepancy may be due to problems with patient recall or with physician over-reporting. The consistent significant differences in physician counselling practices reported by heavy compared with lighter smokers may demonstrate that patient characteristics prompt physicians to implement smoking intervention counselling.

Taken together, these data suggest that much more is required before we are confident that CME training will facilitate effective interventions. Few physicians reported engaging in key intervention activities, and there was little difference in patient reports of physician activities in Comparison and Intervention communities.

To make CME programmes effective for changing provider practices, they should include information about and linkage to a compulsory follow-up component, such as with the use of academic detailing. ${ }^{34}{ }^{35}$ On-site academic detailing could help physicians and ancillary staff with identification of barriers and problem solving, which could enable them to develop effective office systems. More effort is needed to involve other providers and staff in intervention and office systems. The AHCPR smoking cessation guideline ${ }^{4}$ summarised the need for involving ancillary staff noting that "smoking cessation interventions delivered by multiple types of providers markedly increase cessation rates". Ancillary staff can serve as the provider with whom follow-up is arranged, as long as the physician "closes the loop" with a letter or during the next regular patient visit.

In large healthcare organisations, such as hospitals, and in managed-care organisations, administration can play a role in promoting an institutional commitment to delivery of preventive interventions by providers. Several recent initiatives can help to enhance future clinical preventive services in healthcare systems. These include Put prevention into practice, the US Public Health Services programme ${ }^{36}$ and the Canadian guide to clinical preventive healthcare ${ }^{37}$ which can guide organised delivery systems to implement preventive services. New standards developed by accreditation bodies such as the Joint Commission on Accreditation of Healthcare Organisations can facilitate a voluntary systematic approach to prevention. ${ }^{38}$ In addition, implementation by organisations of the AHCPR smoking cessation guideline ${ }^{4}$ can help to enhance preventive services. As well as strategies for healthcare administrators and insurers, the AHCPR guideline recommends the following five strategies for primary-care clinicians.

- Systematically identify all tobacco users at every visit

- Strongly urge all smokers to quit

- Identify smokers willing to make a quit attempt

- Aid the patient in quitting (including setting a date and recommending nicotine replacement therapy)

- Schedule follow-up contact.

These new policy recommendations, if responded to by organisations, can provide important impetus to future educational programmes. They establish clinical tobacco interventions as part of standards of practice, therefore motivating physicians to want to learn more about how to provide effective and efficient help to their patients.

Another important development for encouraging greater use of smoking intervention practices by primary-care physicians is the Health Plan Employer Data and Information Set (HEDIS) 3.0 which includes two measures on smoking. One measure which has already been implemented is for the identification of the percentage of smokers within each managed-care plan who received advice to quit smoking during the reporting year from a plan provider. Another is intended to track cessation rates among members. Awareness of the importance of teaching about tobacco interventions during clinical training in medical school has increased. ${ }^{39-41}$

Guidelines and standards for prevention can potentially overcome many barriers that impede clinicians from implementing optimal intervention on tobacco use by motivating organisational change that may not otherwise occur. $^{36}$ However, organisations must be willing to implement the guidelines and set up the systems needed to facilitate use of the guidelines. Guidelines are only useful when they are implemented. Thus, future efforts to enhance smoking intervention practices in 
primary-care settings can only occur in a climate where voluntary and mandated changes are occurring simultaneously to promote prevention. A new accountability could increase the need for clinician education about brief smoking intervention and for ancillary staff training and ultimately improve our effectiveness in helping smokers quit. Physicians and other providers are in a position to help patients stop smoking; with skills, supportive office systems, and incentives, they can be effective. These preventive intervention practices must become an essential part of competent medical practice and healthcare systems.

The research reported in this paper was funded by the National The research reporch Cancer Institute. Our colleagues at Information Managemen sites, the coordinating center, Information Mational Cancer Institute contributed Services, Inc., and
greatly to this work.

1 COMMIT Research Group. Community Intervention Trial for Smoking Cessation (COMLUT): summary of design for Smoking Cessation (Cancer Inst 1991;83:1620-8.

2 Ockene J, Lindsay E, Berger L, Hymowitz N. Health care providers as key change agents in the Community Educ 1991:11:223-37.

$Q$ Commun Health Educ 1991;11:223-37.

3 Manley M, Epps R, Husten C, Glynn T, Shopland D. Clinical interventions in tobacco control: a National Cancer Institute trainin

4 Fiore MC, Bailey WC, Cohen SJ, et al. Smoking cessation. Clinical Practice Guideline No 18. Rockville, Maryland: US Department of Health and Human Services, Public Health Service, Agency for Health Care Policy and Research, April 1996. (AHCPR Publication No 96-0692.)

5 Crooks C, Kenney E, Elder J, Levitz M, Bal D. Tobacco control activities of primary care physicians

6 Ockene J. Physician-delivered interventions for smoking cessation: strategies for increasing effectiveness. Prev Med 1987;16:723-37.

7 Wilson D, Taylor W, Gilbert $R$, et al. A randomized trial of a family physician intervention for smoking cessation. family physician interven

8 Cohen SJ, Christen AG, Katz BP, et al. Counseling medical and dental patients about cigarette smoking: the impact of nicotine gum and

9 Cohen S, Stokey G, Katz B, Drook C, Smith A. EncouragCohen S, Stoke quit. Ann ing primary care physicians

10 Ockene J, Kristeller J, Goldberg R, et al. Increasing the effcacy of physician-delivered smoking intervention: randomized clinical trial. $f$ Gen Intern Med 1991;6:1-8.
,

11 Janz NK, Becker MH, Kirsch JP, Eraker Wooliscrof Jontion in an outpatient setting. Am $\mathcal{F}$ Public Health 1987;77:849-51.

12 Kottke T, Brekke M, Solberg L, Hughes J. A randomized trial to increase smoking intervention by physicians: doctors helping smokers, round 1. $f A M A 1989 ; 261: 2101$ 6.

13 Cummings S, Coates TJ, Richard RJ, et al. Training physicians in counseling about smoking cessation: a randphysicias in couns "Ouit for Life" program. Ann Intern Med 1989;110:640-7.

14 Russell N, Roter D. Health promotion counseling of care visits. Am $\mathcal{F}$ Public Health 1993;83:979-82.

15 Ockene J, McBride P, Sallis J, Bonollo D, Ockene I. Synthesis of lessons learned from cardiopulmonary preventive interventions in healthcare practice settings. Ann Epidemio 1997;57:532-45.

16 Davis D, Thompson M, Oxman A, Haynes B. Evidence for the effectiveness of CME: a review of 50 randomized conthe effectiven. $\Im A M A$ 1992;268:1111-17.

17 Wallack L Sciandra R. Media advocacy and public education in the Community Intervention Trial for Smok- ing Cessation (COMMIT). Int $Q$ Commun Hialth Educ 1991;11:271-90.

18 Sorensen G, Glasgow RE, K C. Promoting smoking contro through worksites in the Community Intervention Trial for Smoking Cessation (CON.

19 Pomrehn P, Sciandra R, Shipley R, Lynn IF, Lando H Pomrehn $P$, Sciandra $R$, Shancing resources for smoking cessation through comEnchancing resources for smoking cessation through community intervention: COMMIT as

20 Lindsay E, Hymowitz N, Mecklenburg R, Churchill L Poland B. Activities to promote health care providers as participants in community-based tobacco control. Community based interventions for smokers: the COMMIT ficld experience. based interventions lord: National Institutes of Health, 1995:133-151. (NIH Publication No 95-4028.)

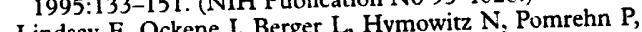
Wilson D. The role of physicians and dentists in the ComWilson $\mathrm{D}$. The role of phing munity Intervention Trial for smoking cessacion (COMMIT). In: Tobacco and the clinician: interventions for medical and dental practice. Bethesda, Maryland. (NIH Publication No tutes of $\mathrm{H}$

94-3693.) Cummings $\mathrm{K}$, Lynn W, Giffen C, Corle D,

22 Mattson $M$, Cummings $K$, Lynn W, Giffen $C$, Corle $D$, Pechacek T. Evaluation plan for the commun Health Educ tion trial for smoking

1990-91;11:271-90.

COMMT): I. Cohort results for Smoking Cessation (COM intervention. Am $f$ Public Health. 1995;85:183-92.

24 Edeark: Marce Dekker, 1987.

$25 S A S$ users guide-statistics, release 6.5. Carey, North Carolina: SAS Institute, 1993.

26 Parsons J, Warnecke R, Czaja R, Barnsley J, Kaluzny A. Factors associated with response rates in a national survey of primary care physicians. Eval Rev 1994;18:756-66.

27 Sobal J, Ferentz K. Comparing physicians' responses to the first and second mailings of a questionnaire. Eval Health Professions 1989;12:329-39.

28 Guadagnoli $E$, Cunningham $S$. The effects of nonresponse and late response on a survey of physician attitudes. Eval Health Professions 1989;12:318-28.

29 Ano 1992 igares in the definition of current cigarette 1992, and MMWR 1994;43:342-6.

30 Lindsay $E$, Ockene J, Hymowitz N, Giffen C, Berger L, Pomrehn P. Physicians and smoking cessation: a survey of office procedures and practices in the community intervention trial for smoking cessation. Arch Fam Med 1994;3:341-8.

31 Ockene I, Ockene J, Hebert J, et al. Physician counseling for diet modification in a lipid intervention trial. In: American Heart Association Scientific Sessions. Atlanta, Georgia American Heart Association, 1993.

32 Burgess A, Tierney J. Bias due to nonresponse in a mail survey of Rhode Island physician

33 McPhee S, Bird J, Fordham D, Rodnick J, Osborn E. Promoting cancer prevention activities by primary care physicians: results

34 Daly M, Balshem M, Sands C, James J, Workman S, Daly $M$, Balshem $M$, Engstrom P. Academic detailing; a
CME. ₹ Cancer Educ 1993;8:273-80.

35 Soumerai S, Avorn J. Principals of educational outreach ("academic detailing") to improve clinical decisio making. $¥ A M A$ 1990;263:549-56.

36 US Department of Health and Human Services. Clinician's handbook of preventive services: put prevention into practice. handbook of preventive services. pus prevention, 1994.

37 Canadian Task Force on the Periodic Health Examination The Canadian guide co clinical preventive health care. Ottawa: Health Canada, 1994.

38 Larose S. JCAHO initiates development of performance Larose S. JCAHO initiates dervices. Inside Prev Cure 1995; 2:7-8.

39 Fiore $M$, Epps $R$, Manley $M$. A missed opportunity: teaching medical students to help their patients successfully quit smoking. $¥ A M A$ 1994;271:624-6.

40 Ockene J, Ockene I, Kabat-Zinn J, Greene H, Frid D. Teaching risk-factor counseling skills to medical students, Teaching risk-factor counseling $f$ Prev Med 1990;suppl house staff 41 Usatine $R$, Wilkes $M$, Slavin $S$, Wilkerson L. A model Med 1996;71:S96-8. 